\title{
De-Doped Polyaniline as a Mediating Layer Promoting In-Situ Growth of Metal-Organic Frameworks on Cellulose Fiber and Enhancing Adsorptive-Photocatalytic Removal of Ciprofloxacin
}

\author{
Xinyu Hou, Lijian Sun, Ying Hu, Xianhui An and Xueren Qian* \\ Key Laboratory of Bio-Based Material Science \& Technology, Northeast Forestry University, \\ Ministry of Education, Harbin 150040, China; hxy@nefu.edu.cn (X.H.); lantian0308@nefu.edu.cn (L.S.); \\ huying@nefu.edu.cn (Y.H.); anxianh509@163.com (X.A.) \\ * Correspondence: qianxueren@nefu.edu.cn; Tel.: +86-13-(304)642-918
}

check for updates

Citation: Hou, X.; Sun, L.; Hu, Y.; An X.; Qian, X. De-Doped Polyaniline as a Mediating Layer Promoting In-Situ Growth of Metal-Organic

Frameworks on Cellulose Fiber and Enhancing Adsorptive-Photocatalytic Removal of Ciprofloxacin. Polymers 2021, 13, 3298. https://doi.org/ $10.3390 /$ polym13193298

Academic Editor: Muhammad Salahuddin Khan

Received: 23 August 2021

Accepted: 23 September 2021

Published: 27 September 2021

Publisher's Note: MDPI stays neutral with regard to jurisdictional claims in published maps and institutional affiliations.

Copyright: (C) 2021 by the authors Licensee MDPI, Basel, Switzerland. This article is an open access article distributed under the terms and conditions of the Creative Commons Attribution (CC BY) license (https:// creativecommons.org/licenses/by/ $4.0 /)$
Abstract: New kinds of inorganic-organic hybrid porous materials, metal-organic frameworks (MOFs), have shown great application potential in various fields, but their powdery nature limits their application to a certain extent. As a green and renewable biomass material in nature, cellulose fiber (CelF) has the advantages of biodegradability, recyclability and easy processing, and can be used as an excellent flexible substrate for MOFs. However, the efficient deposition of MOFs on CelF is still a great challenge for the development of this new material. Herein, polyaniline (PANI) and de-doped PANI (DPANI) with rich functional groups as a mediating layer was proposed to promote the in-situ growth and immobilization of some MOFs on CelF. The PANI (especially DPANI) layer greatly promoted the deposition of the four MOFs, and more encouragingly, significantly promoted the in-situ growth and nanocrystallization of MIL-100(Fe). MIL-100(Fe)@DPANI@CelF was selected as an adsorbent-photocatalyst to be used for the adsorptive-photocatalytic removal of ciprofloxacin (CIP) in water. The removal efficiency of CIP by MIL-100(Fe)@DPANI@CelF reached 82.78\%, and the removal capacity of CIP was as high as $105.96 \mathrm{mg} \mathrm{g}^{-1}$. The study found that DPANI had a synergistic effect on both the in-situ growth of MIL-100(Fe) on CelF and the adsorption-photocatalysis of CIP in water. The universal platform of PANI-mediated in-situ growth and immobilization of MOFs on CelF constructed in this study widens the road for the development of MOF@CelF composites.

Keywords: cellulose fiber; metal-organic frameworks; polyaniline; de-doping; adsorption; photocatalysis; ciprofloxacin

\section{Introduction}

Metal-organic Frameworks (MOFs) are a class of crystalline materials that consist of coordination bonds between transition-metal cations and multidentate organic linkers [1], which have the advantages of both inorganic compounds and organic polymers. In recent years, MOFs and their composites have shown great application potential and value in many fields, such as conduction [2], antibacterial applications [3], gas storage [4], water purification [5], drug delivery [6], adsorption [7,8], photocatalysis [9], etc. However, the crystalline nature of MOFs determines their powder form, and their recycling and processability are affected to a certain extent, significantly limiting their application. As a green and renewable resource in nature, cellulose has the advantages of biodegradability, recyclability, high flexibility and easy processing [10-12], which make it particularly suitable as an excellent flexible carrier of MOFs. At the same time, the existence of MOFs will also give cellulose many new functions, which can be described as killing two birds with one stone.

Up to now, there has been positive progress in the research and development of cellulose fiber-based MOF (MOF@CelF) composites. Paper and pulp fiber [13], cotton fabric [14,15], nanocellulose [16,17], aerogel [18,19] and bacterial cellulose [20] have all been used as substrates for the loading of MOFs. However, the loading of MOFs on some 
untreated CelF (e.g., pulp fibers and cotton fibers) is generally low in amount and weak in binding affinity. Therefore, some studies were conducted to promote the loading of MOFs on CelF, to a certain extent, by means of carboxymethylation [21,22], atomic layer deposition [23], citric acid modification [24], (3-aminopropyl)triethoxysilane (APTES) and 3-glycidyloxypropyltrimethoxysilane (GPTMS) as connecting substances [25-27], polydopamine as an intermediate layer [20], etc. However, the degradation of CelF is inevitable during carboxymethylation, and atomic layer deposition has high requirements for equipment. At the same time, there are few studies on the efficient binding of MOFs with CelF. There is an urgent need to find an efficient and simple universal method to promote the in-situ growth and immobilization of MOFs on CelF on the basis of maintaining the inherent morphological characteristics of CelF.

As a common conductive polymer, polyaniline (PANI) has excellent chemical and thermal stability, and it shows strong adsorption on metal ions [28]. Meanwhile, its photocatalytic efficacy is also phenomenal [29]. ZIF-8, ZIF-67, HKUST-1 and MIL-100(Fe), as four MOFs that can be generated under green synthesis conditions at room temperature, are not only in line with the concept of sustainable development, but also have great potential for the development of emerging CelF-based composites.

Ciprofloxacin (CIP) is a widely used fluoroquinolone that is frequently detected in different natural water bodies [30]. Therefore, it is of great urgency to develop effective techniques to remove CIP from aqueous environments and mitigate its inherent risks to ecosystems [31]. CIP can be removed by means of physical adsorption [31], chemical oxidation [30] and photodegradation [32]. Among the four above-mentioned MOFs, MIL-100(Fe) is often used as a part of photocatalytic composites due to the existence of $\mathrm{Fe}^{3+}[33,34]$, and shows excellent removal ability for CIP in water; therefore, it plays a distinctive role in water environment treatment.

In this work, the promoting effect of PANI and de-doped PANI as a mediating layer on the in-situ growth and immobilization of the four MOFs (ZIF-8, ZIF-67, HKUST-1 and MIL-100(Fe)) on CelF (i.e., bleached softwood pulp) were investigated. Firstly, a thin PANI layer, with a large number of quinone nitrogen structures as a mediator, was formed in-situ on CelF to provide rich nucleation sites for the in-situ growth of MOFs. Then, the PANI@CelF was treated by ammonia to obtain the de-doped PANI@CelF (abbreviated as DPANI@CelF), and the above-mentioned four MOFs were further in-situ grown on the DPANI@CelF. MIL-100(Fe)@DPANI@CelF was used as a novel adsorptive photocatalyst to treat CIP wastewater. The effect of the MIL-100(Fe) deposition ratio and the DPANI layer on the synergistic adsorptive-photocatalytic removal of CIP was discussed.

\section{Experiment}

\subsection{Materials and Reagents}

Cellulose fiber (CelF, Canadian bleached kraft softwood pulp board) was kindly provided by Mudanjiang Hengfeng Paper Co., Ltd. (Mudanjiang, China), and beaten to $37^{\circ}$ SR using a PL4-2 speed governing beater before use. Ferrous chloride tetrahydrate ( $\geq 99.7 \%$ ) was produced by Tianjin Guangfu Technology Development Co., Ltd. (Tianjin, China), cobalt nitrate hexahydrate (AR, 99\%) by Aladdin Biochemical Technology Co., Ltd. (Shanghai, China), zinc nitrate hexahydrate (AR, 99\%) by Tianjin Damao Chemical Reagent Factory (Tianjin, China), copper acetate $(\geq 99.0 \%)$ by Zhiyuan Chemical Reagent Co., Ltd. (Tianjin, China), 2-methylimidazole (2-MI, $\geq 98.0 \%$ ) by Guangfu Fine Chemical Research Institute (Tianjin, China), trimesic acid $\left(\mathrm{H}_{3} \mathrm{BTC}\right.$, 98\%) by Macklin Biochemical Co., Ltd. (Shanghai, China), sodium hydroxide $(\geq 96.0 \%)$ by Tianda Chemical Reagent Factory (Tianjin, China), absolute ethanol $(\geq 99.7 \%)$ by Yongda Chemical Reagent Co., Ltd. (Tianjin, China), hydrochloric acid (diluted to $0.6 \mathrm{M}$ before use) and ammonia (diluted to $0.1 \mathrm{M}$ before use) by Kermel Chemical Reagent Co., Ltd. (Tianjin, China), aniline (ANI, purified by vacuum distillation before use) and hydrogen peroxide (30\%) by Tianli Chemical Reagent Co., Ltd. (Tianjin, China), and ammonium persulfate (APS, $\geq 98.0 \%$ ) by Fuchen Chemical 
Reagent Co., Ltd. (Tianjin, China). Ciprofloxacin hydrochloride (CIP) was of USP grade $(\geq 88.5 \%)$.

\subsection{Preparation of PANI@CelF and DPANI@CelF}

Typically, $2 \mathrm{~g}$ of CelF (oven dry basis), $180 \mathrm{~mL}$ of $\mathrm{HCl}(0.6 \mathrm{M})$ solution and $1 \mathrm{~mL}$ of ANI were added successiely to a $500 \mathrm{~mL}$ three-necked bottle in an ice-water bath $\left(0-5{ }^{\circ} \mathrm{C}\right)$, and stirred for $40 \mathrm{~min}$ to ensure that the CelF dispersed evenly in the reaction medium. Then, $20 \mathrm{~mL}$ of $\mathrm{HCl}(0.6 \mathrm{M})$ solution containing $4.9 \mathrm{~g}$ APS was slowly dropped into the above system under stirring. After $105 \mathrm{~min}$, the treated fibers were filtered and washed with tap water to obtain PANI@CelF.

The resultant PANI@CelF and $200 \mathrm{~mL}$ ammonia solution $(0.1 \mathrm{M})$ were put into a $500 \mathrm{~mL}$ three-necked bottle and stirred for $1 \mathrm{~h}$ for de-doping treatment. The product was filtered and washed with tap water until the filtrate was colorless to obtain the de-doped PANI@CelF (abbreviated as DPANI@CelF).

\subsection{Preparation of MOF Composites}

The preparation of MOF composites is briefly described, taking MOFs@CelF composites as examples. For the preparation of MOFs@PANI@CelF and MOFs@DPANI@CelF, it was only necessary to replace CelF with PANI@CelF and DPANI@CelF. For comparison, powdery MOFs were also prepared without adding CelF.

\subsubsection{Preparation of ZIF-8@CelF and ZIF-67@CelF}

Typically, $2 \mathrm{~g}$ of CelF (oven dry basis) and $4 \mathrm{mmol}$ of zinc nitrate hexahydrate were put into a $500 \mathrm{~mL}$ three-necked bottle that was placed in a water bath at a temperature of $25^{\circ} \mathrm{C}$, and then $150 \mathrm{~mL}$ of deionized water was added. After stirring for $3 \mathrm{~h}, 50 \mathrm{~mL}$ of aqueous solution, containing $240 \mathrm{mmol}$ of 2-MI, was slowly dropped into the above system. After $6 \mathrm{~h}$ of reaction, the product was filtered and washed with $10 \mathrm{~L}$ of deionized water to obtain the ZIF-8@CelF composite.

The preparation conditions of ZIF-67@CelF were similar to those of ZIF-8@CelF. Only $4 \mathrm{mmol}$ of cobalt nitrate hexahydrate was used to replace zinc nitrate hexahydrate.

\subsubsection{Preparation of HKUST-1@CelF}

Typically, $2 \mathrm{~g}$ of CelF (oven dry basis), $6 \mathrm{mmol}$ of copper acetate and $180 \mathrm{~mL}$ of deionized water were put into a $500 \mathrm{~mL}$ three-necked bottle that was placed in a water bath at a temperature of $25^{\circ} \mathrm{C}$, and the mixture was stirred for $3 \mathrm{~h}$. Then, $20 \mathrm{~mL}$ of absolute ethanol solution, containing $4 \mathrm{mmol}$ of $\mathrm{H}_{3} \mathrm{BTC}$, was added dropwise to the above system and continuously stirred for $3 \mathrm{~h}$. The product was filtered and washed with $10 \mathrm{~L}$ of deionized water to obtain HKUST-1@CelF.

\subsubsection{Preparation of MIL-100(Fe)@CelF}

Typically, $2 \mathrm{~g}$ of CelF (oven dry basis) and $5.7 \mathrm{mmol}$ of ferrous chloride tetrahydrate were put into a $500 \mathrm{~mL}$ three-necked bottle, then $150 \mathrm{~mL}$ of deionized water was added, and the mixture was stirred at $23{ }^{\circ} \mathrm{C}$ for $3 \mathrm{~h}$ to ensure the sufficient adsorption of $\mathrm{Fe}^{2+}$ by CelF. Then, $3.8 \mathrm{mmol}$ of $\mathrm{H}_{3} \mathrm{BTC}$, dissolved in $50 \mathrm{~mL}$ of aqueous solution containing $11.4 \mathrm{mmol}$ of $\mathrm{NaOH}$, was slowly added to the three-necked bottle, and the mixture was constantly stirred for $24 \mathrm{~h}$. The product was filtered and washed with $10 \mathrm{~L}$ of deionized water to obtain MIL-100(Fe)@CelF.

\subsection{Calculation of MOF Deposition Ratio}

The as-prepared product was dried in an oven at $105^{\circ} \mathrm{C}$ for $6 \mathrm{~h}$. After cooling for $30 \mathrm{~min}$ in a dryer, the mass was measured. The deposition ratio $(D, \%)$ of MOF was calculated according to the following formula:

$$
D=\left(M_{2}-M_{1}\right) / M_{0} \times 100 \%
$$


where $M_{0}$ is the original mass of CelF ( $\left.\mathrm{g}\right), M_{1}$ is the mass of the composite coated PANI or DPANI layer $(\mathrm{g})$, and $M_{2}$ is the mass of the composite deposited MOF (g).

\subsection{Adsorption-Photocatalysis Experiment}

In order to compare the CIP removal ability of the composites with different MIL100(Fe) loading amounts, MIL-100(Fe)@CelF and MIL-100(Fe)@DPANI@CelF samples with 6 loading levels were prepared by changing the $\mathrm{FeCl}_{2}$ dose $(2.85,5.7,8.55,11.4,14.25$ and $17.10 \mathrm{mmol}$ ) at 1.5:1:3 of the constant $\mathrm{FeCl}_{2}: \mathrm{H}_{3} \mathrm{BTC}: \mathrm{NaOH}$ molar ratio. The above products are marked as T1-T6 in the order of $\mathrm{FeCl}_{2}$ dose from low to high.

CIP aqueous solution (160 mg L $\mathrm{m}^{-1}$ ) was prepared, and $200 \mathrm{~mL}$ were taken each time for subsequent testing. Firstly, $0.25 \mathrm{~g}$ of sample (DPANI@CelF, MIL-100(Fe)@CelF and MIL-100(Fe)@DPANI@CelF, oven dry basis) was added to the above CIP aqueous solution and stirred at $500 \mathrm{rpm}$ for $60 \mathrm{~min}$ at room temperature and in dark condition to reach the adsorption equilibrium. Then, $250 \mu \mathrm{L}$ of $30 \% \mathrm{H}_{2} \mathrm{O}_{2}$ was added and the system was placed under a CEL-PF300L-3A xenon sunlight-simulating lamp (Beijing China Education AuLight Technology Co., Ltd., Beijing, China) for photocatalytic reaction for $2 \mathrm{~h}$. During photocatalysis, the working current of xenon lamp was adjusted to $20.7 \mathrm{~A}$, and the distance between the lamp and the liquid surface was about $10 \mathrm{~cm}$. Samples were taken every 10 min during adsorption and every $20 \mathrm{~min}$ during photocatalysis. CIP concentration was measured by a TU-1950 UV-Vis spectrophotometer at $277 \mathrm{~nm}$.

In order to calculate the removal efficiency of CIP by the composites, the absorbance at $0.48,1.04,1.52,2.00,2.48,3.04,3.52$ and $4.00 \mathrm{mg} \mathrm{L}^{-1} \mathrm{CIP}$ concentrations were measured and the CIP standard working curve was obtained (Figure 1). After linear fitting, the obtained standard working curve equation of CIP was $y=0.2137 x-0.0704\left(R^{2}=0.991\right)$, where $y$ is the absorbance of CIP at $277 \mathrm{~nm}$ and $x$ is the mass concentration of CIP $\left(\mathrm{mg} \mathrm{L}^{-1}\right)$.

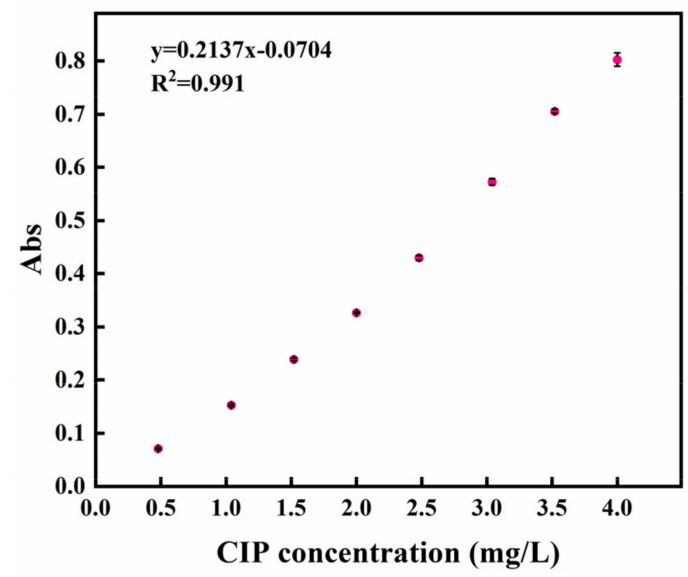

Figure 1. CIP standard working curve.

According to the CIP standard curve equation, the CIP concentration corresponding to each sampling stage was calculated, and the removal efficiency $(R)$ of CIP by the composite was obtained. The following calculation formula for $R(\%)$ was used:

$$
R=\left(C_{0}-C_{\mathrm{t}}\right) / C_{0} \times 100 \%
$$

where $C_{0}$ is the initial mass concentration of $\mathrm{CIP}\left(\mathrm{mg} \mathrm{L}^{-1}\right)$, and $C_{\mathrm{t}}$ is the mass concentration of CIP at time $t\left(\mathrm{mg} \mathrm{L}^{-1}\right)$.

\subsection{Characterization}

The crystalline nature of the samples was analyzed using an X'Pert3 Powder X-ray diffractometer (Panaco, Holland). The ray wavelength was $0.154 \mathrm{~nm}$, the voltage was $40 \mathrm{kV}$, the current was $40 \mathrm{~mA}$, the scanning range was $5-50^{\circ}$, and the scanning speed was $5^{\circ} \mathrm{min}^{-1}$. Scanning electron microscopy (Zeiss Supra 55, Germany) was used to analyze 
the morphology of the samples. The samples containing Fe were coated with gold, and the surface element composition of the samples was analyzed by energy dispersive $\mathrm{X}$-ray spectroscopy (EDS). XPS photoelectron spectroscopy (Thermo Scientific K-Alpha, USA) was used to measure to the element composition and valence information of samples using $\mathrm{Al}$ $\mathrm{K} \alpha \mathrm{X}$-ray $(1486.6 \mathrm{eV})$ as the excitation source. FTIR spectra were recorded using a Thermo Scientific Nicolet 10 FTIR spectrometer (USA) in the frequency range of $4000-600 \mathrm{~cm}^{-1}$.

\section{Results and Discussion}

\subsection{Design and Preparation of MOF@DPANI@CelF Composites}

Herein, MIL-100(Fe)@DPANI@CelF composite is taken as an example to briefly illustrate the principle and process of the composite preparation, as shown in Scheme 1. Firstly, a firm PANI layer was formed on the surface of CelF by in-situ polymerization, and then the PANI-mediating layer was de-doped by excessive ammonium hydroxide solution to expose a large number of quinone nitrogen atoms. Next, $\mathrm{Fe}^{2+}$ ions were adsorbed on the de-doped PANI with rich binding sites. Subsequently, the deprotonated ligand $\left(\mathrm{BTC}^{3-}\right)$ was added to prompt the in-situ growth and immobilization of MIL-100(Fe) on the DPANI@CelF substrate. Finally, the resulting composite was used in subsequent adsorptive-photocatalytic experiments to remove CIP in the water environment.

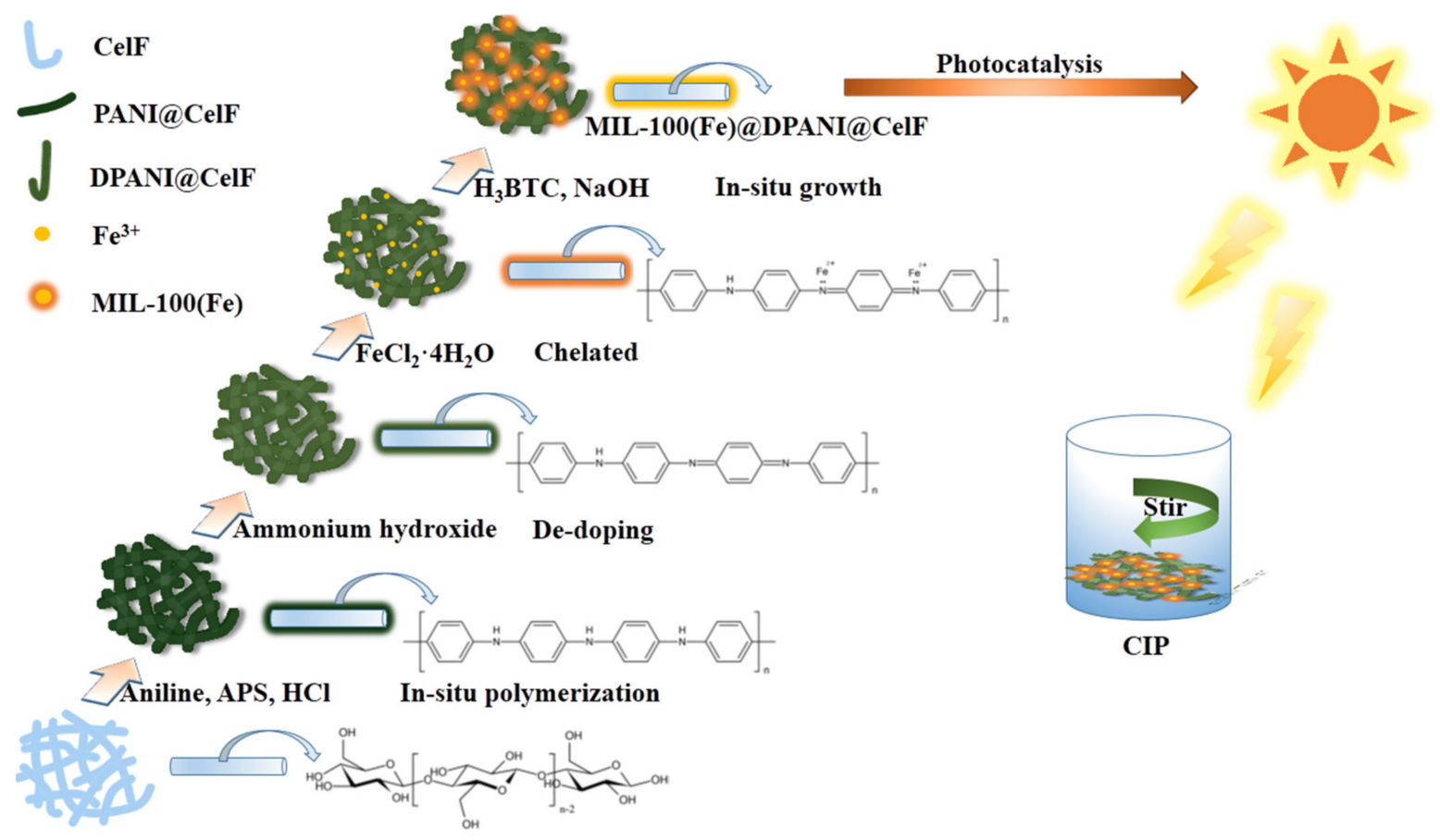

Scheme 1. Schematic illustration of the preparation and application of MIL-100(Fe)@DPANI@CelF.

\subsection{Effect of PANI and DPANI as Mediating Layer on Growth of MOFs on CelF}

The four MOFs (ZIF-8, ZIF-67, HKUST-1 and MIL-100(Fe)) were in-situ deposited on the three CelF substrates (CelF, PANI@CelF and DPANI@CelF), respectively, and the deposition ratios are shown in Figure 2a. The results show that the existence of the PANI layer significantly improved the in-situ growth and immobilization of the other three MOFs, except for HKUST-1 on CelF. For HKUST-1, no promoting effect of PANI was observed, perhaps due to the micron-rod structure of HKUST-1 [35]. However, the DPANI layer obtained by further de-doping treatment played a positive role in promoting the in-situ growth and immobilization of the four above-mentioned MOFs on CelF. More encouragingly, it was found that the PANI/DPANI layer had an amazing promoting effect on the deposition of MIL-100(Fe) compared with the three other MOFs. 


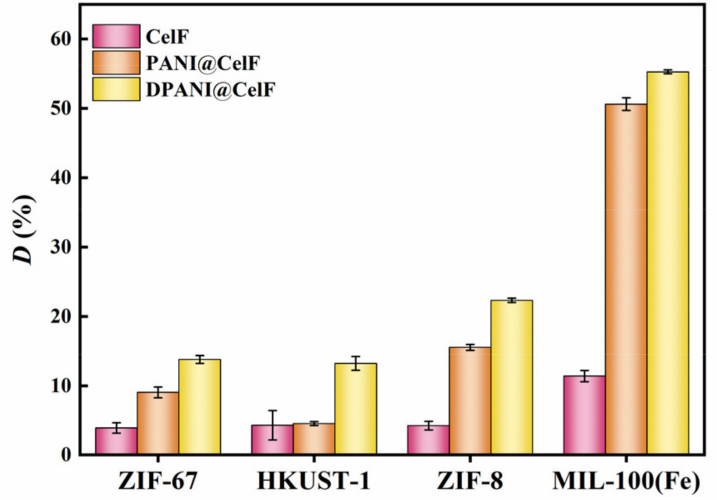

(a)

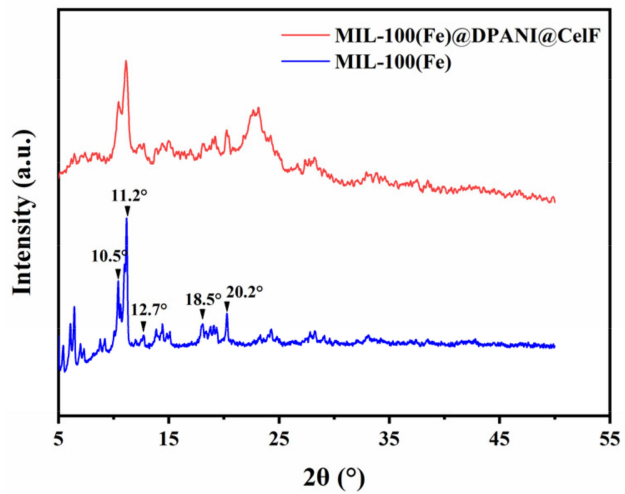

(c)

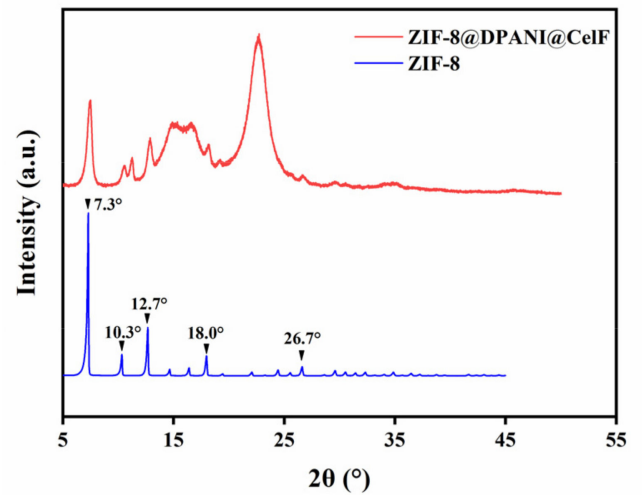

(e)

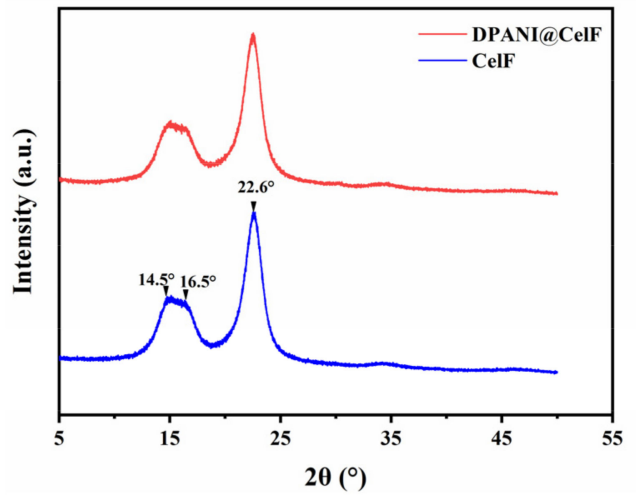

(b)

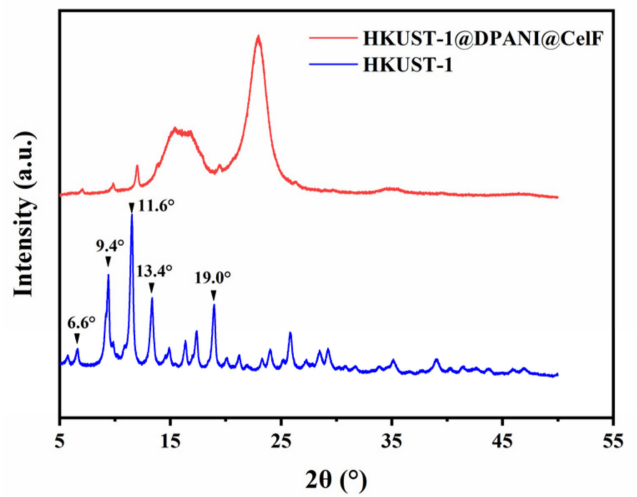

(d)

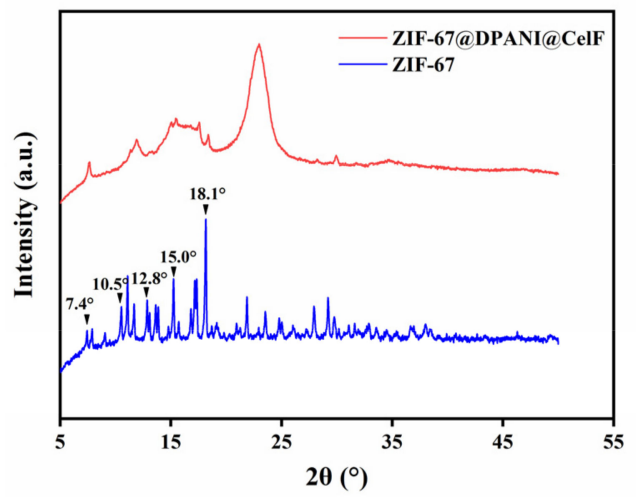

(f)

Figure 2. (a) Comparison of MOFs' growth on three CelF substrates; (b) XRD patterns of CelF and DPANI@CelF; (c-f) XRD patterns of MOFs and their composites.

Because of their unique crystalline nature, the formation of MOFs is easily confirmed through the comparison of XRD patterns. As shown in Figure 2b, DPANI@CelF exhibited no significant difference in terms of XRD results as compared with CelF, which shows that the existence of the DPANI layer had no effect on the original structure of CelF. The peaks at $2 \theta=10.5^{\circ}, 11.2^{\circ}, 12.7^{\circ}, 18.5^{\circ}, 19.2^{\circ}$ and $20.2^{\circ}$ were the characteristic diffraction peaks of MIL-100(Fe). In Figure 2c, it can be seen that the diffraction peaks of MIL100(Fe)@DPANI@CelF and pure MIL-100(Fe) powder prepared under the same conditions were consistent with those reported in the literature [36], which preliminarily confirms the generation of MIL-100(Fe) on DPANI@CelF. Figure 2d-f demonstrate that HKUST-1, ZIF-8 and ZIF-67 particles were in-situ deposited on DPANI@CelF although some peaks were weak due to the relatively low proportion of MOFs in the composites $[35,37,38]$. 


\subsection{Structure and Morphology of MIL-100(Fe)@DPANI@CelF}

As confirmed by the above results, the loading amount of MIL-100(Fe) on DPANI@CelF was considerable. Next, MIL-100(Fe)@DPANI@CelF, as the main research object, is discussed in detail. Figure 3a-f show the surface morphology of PANI@CelF and DPANI@CelF, respectively, and amorphous PANI/DPANI particles with sizes of about $300 \mathrm{~nm}$, attached to the fiber surface, can be observed. It can also be observed that both the surface and the pits of the fiber were covered with PANI/DPANI particles. The pits were typical of the structure of the fiber surface, i.e., thin areas without secondary walls. Figure $3 g-1$ show the distribution of MIL-100(Fe) on CelF and DPANI@CelF, respectively. It is obvious that the micron-scale irregular MIL-100(Fe) particles, with sizes of about $1 \mu \mathrm{m}$, were unevenly distributed on the CelF surface, while the MIL-100(Fe) particles on the DPANI@CelF surface were generally nanoscale (less than $100 \mathrm{~nm}$ ). This may be because the DPANI@CelF had more nucleation sites, which promoted the in-situ growth and immobilization of more MIL-100(Fe) particles on the DPANI@CelF surface and limited the growth of the larger crystals, to a certain extent, due to the space-charge-limited effect. Nanoscale MIL$100(\mathrm{Fe})$ particles had much larger specific surface areas, which also positively promoted the follow-up adsorption-photocatalysis. As depicted in Figure $3 \mathrm{~m}-\mathrm{p}$, the element maps of MIL-100(Fe)@DPANI@CelF show the uniform distribution of Fe, C, O and N elements on the surface of the composite, which further indicates the successful synthesis of MIL-100(Fe) on the surface of DPANI@CelF.

The elemental composition and valence states of three samples (MIL-100(Fe), MIL100(Fe)@DPANI@CelF and DPANI@CelF) were measured by XPS, and the results are shown in Figure 4a. The peaks of $\mathrm{C} 1 \mathrm{~s}(285.05 \mathrm{eV}), \mathrm{O} 1 \mathrm{~s}(532.08 \mathrm{eV})$, and Fe 2p (725.08 eV, $711.08 \mathrm{eV}$ ) can be observed in the XPS spectrum of MIL-100(Fe), and the peaks of C 1s, O 1s and N 1s (399.08 eV) are visible in the XPS spectrum of DPANI@CelF, and all of the peaks (C 1s, O 1s, N 1s and Fe 2p) are present in the XPS spectrum of MIL-100(Fe)@DPANI@CelF sample. The $\mathrm{C} / \mathrm{Fe}$ atomic ratio of the prepared MIL-100(Fe) was 10.9:1, which implies that each $\mathrm{Fe}^{3+}$ ion was coordinated with only about one $\mathrm{H}_{3} \mathrm{BTC}$ ligand in the prepared MIL-100(Fe).

The FTIR spectra of CelF, DPANI@CelF, MIL-100(Fe) and MIL-100(Fe)@DPANI@CelF were obtained to analyze their chemical structure, and the results are shown in Figure $4 \mathrm{~b}$. For CelF, the vibrational absorption peak of $\beta$-glycosidic bond appeared at $895 \mathrm{~cm}^{-1}$, the peaks at $1440 \mathrm{~cm}^{-1}$ and $2900 \mathrm{~cm}^{-1}$ corresponded to the stretching vibrations of $\mathrm{H}-\mathrm{C}-\mathrm{H}$ and $\mathrm{C}-\mathrm{H}$, and the absorption peak at $3340 \mathrm{~cm}^{-1}$ was caused by the $-\mathrm{OH}$ vibration (Spectrum A). For DPANI@CelF, the peaks at $1500 \mathrm{~cm}^{-1}$ and $1590 \mathrm{~cm}^{-1}$ correspond to the stretching vibration of benzoquinone structure in PANI [28], and these appeared in addition to the characteristic peaks of CelF, which also indicate the successful assembly of the PANI coating on CelF (Spectrum B). Spectrum D shows the characteristic peaks of MIL-100(Fe). The peaks at $1380 \mathrm{~cm}^{-1}$ and $1450 \mathrm{~cm}^{-1}$ correspond to the symmetric and asymmetric vibration of the -O-C-O-group, respectively, and the vibration peak at $1620 \mathrm{~cm}^{-1}$ can be attributed to the interaction between iron ion and $-\mathrm{COOH}$ [39]. The characteristic peaks of MIL-100(Fe) also appeared in Spectrum C, indicating that the MIL-100(Fe) particles were grown on DPANI@CelF, which is consistent with the results obtained via XRD, SEM and XPS. However, the characteristic peaks of CelF and DPANI were essentially not displayed in Spectrum C, because they were masked by a large amount of MIL-100(Fe) loaded onto DPANI@CelF. 

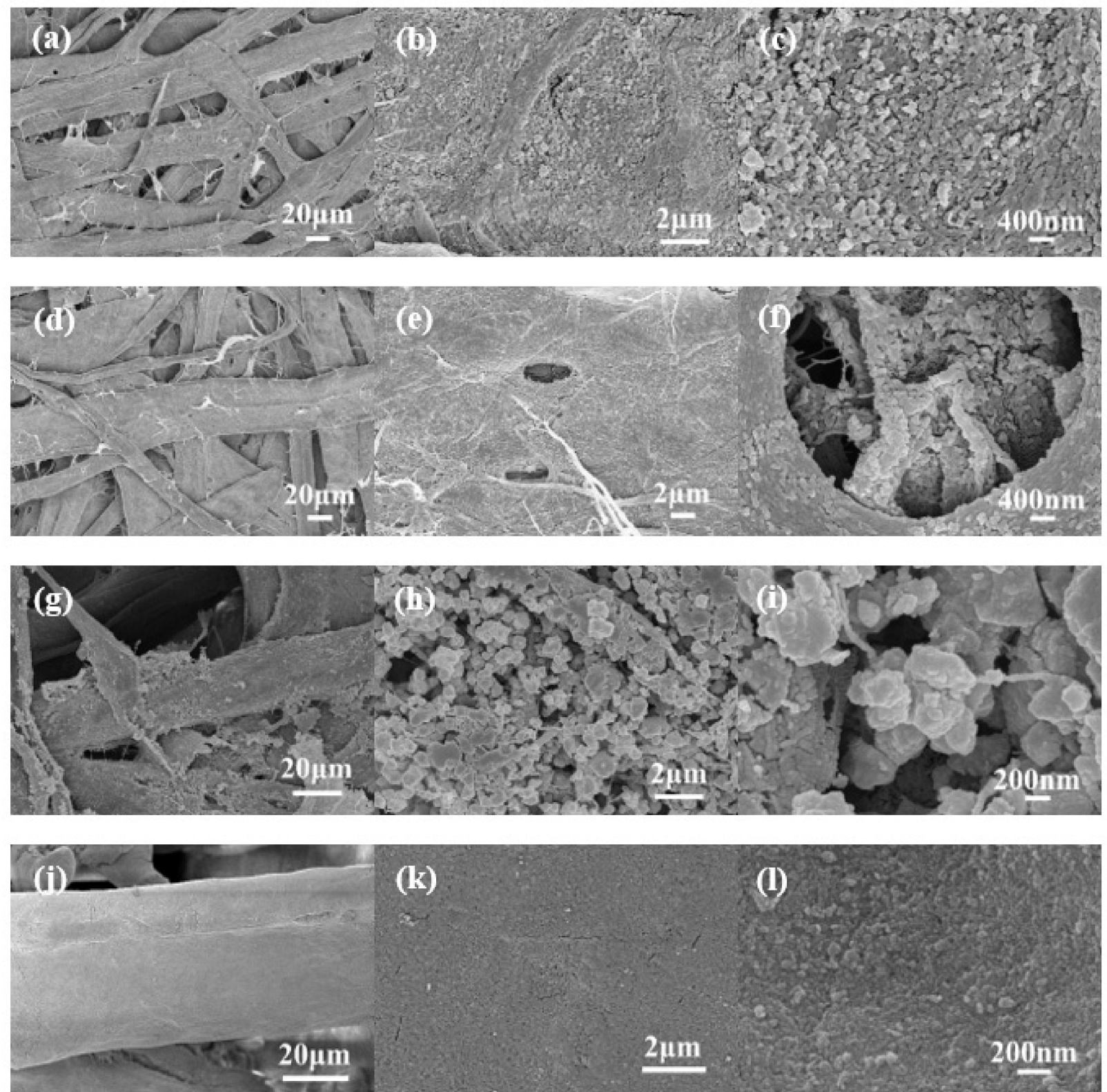

(k)

(1)
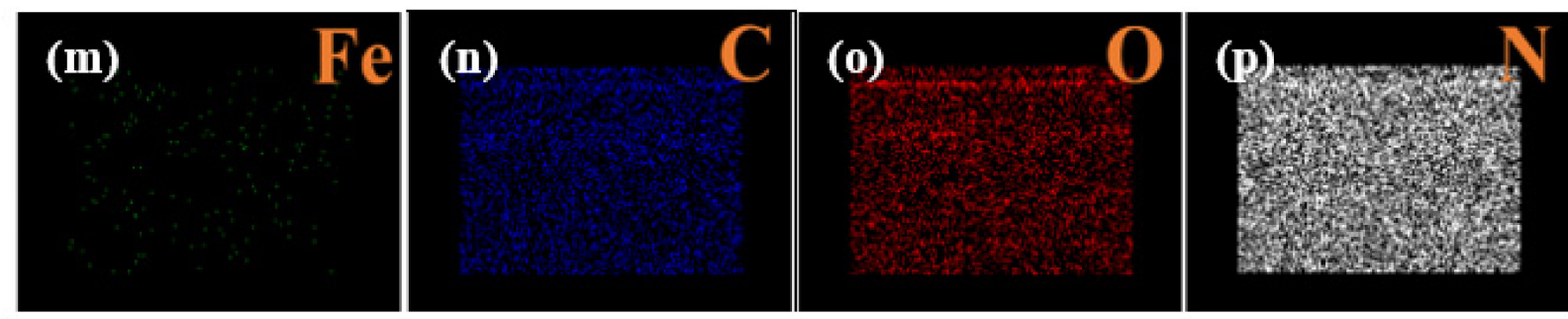

Figure 3. SEM images of PANI@CelF (a-c), DPANI@CelF (d-f), MIL-100(Fe)@CelF (g-i), MIL-100(Fe)@DPANI@CelF (j-1); EDS images of MIL-100(Fe)@DPANI@CelF (m-p). 


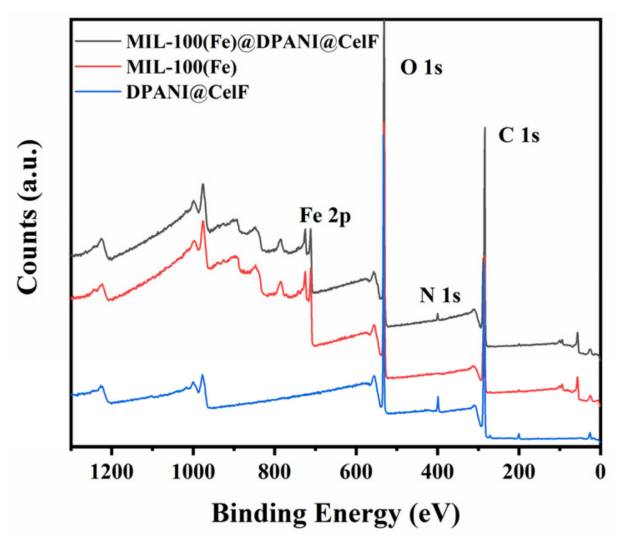

(a)

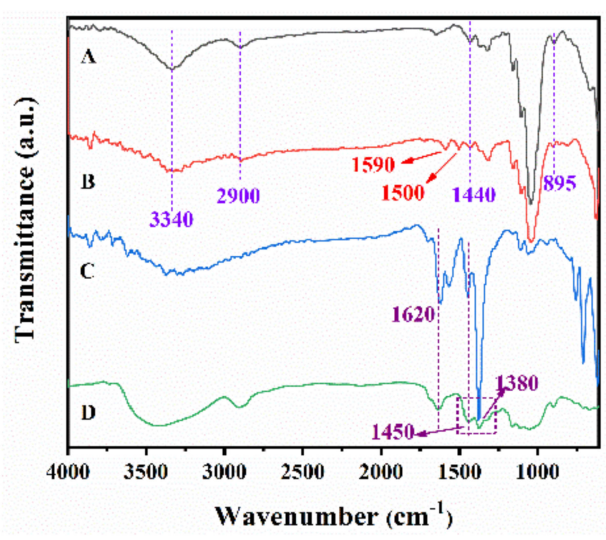

(b)

Figure 4. (a) XPS spectra of DPANI@CelF, MIL-100(Fe) and MIL-100(Fe)@DPANI@CelF; (b) FTIR spectra of CelF (A), DPANI@CelF (B), MIL-100(Fe)@DPANI@CelF (C) and MIL-100(Fe) (D).

\subsection{Removal of CIP in Water by MIL-100(Fe)-Loaded CelF Composites}

Figure 5a shows the MIL-100(Fe) deposition ratios of MIL-100(Fe)@CelF and MIL100(Fe)@DPANI@CelF prepared at different $\mathrm{FeCl}_{2}$ doses. The MIL-100(Fe) deposition ratio almost linearly increased with the increase in the initial $\mathrm{FeCl}_{2}$ dosage, and the MIL-100(Fe) deposition ratios of MIL-100(Fe)@DPANI@CelF were surprisingly higher than those of MIL100(Fe)@CelF in all cases. Figure 5b shows the CIP removal ability of several composites. It was found that DPANI@CelF only had a small amount of adsorption for CIP and had no photocatalytic activity. $\mathrm{H}_{2} \mathrm{O}_{2}$ alone had little effect on CIP removal under experimental light. As the donor of hydroxyl radicals (.OH) in Fenton-like reaction systems, $\mathrm{H}_{2} \mathrm{O}_{2}$ itself does not have photocatalytic activity. Compared with the MIL-100(Fe)@CelF-31\%, which had a similar MIL-100(Fe) deposition ratio, the MIL-100(Fe)@DPANI@CelF-29\% showed higher adsorption capacity and better photocatalytic performance, highlighting the synergistic promotion of DPANI for photocatalytic reactions. The MIL-100(Fe)@DPANI@CelF-120\%, with a higher MIL-100(Fe) deposition ratio, showed higher adsorption capacity and better photocatalytic performance than the MIL-100(Fe)@DPANI@CelF-29\%, indicating that the photocatalytic activity of the composite had a certain dependence on the amount of MIL100(Fe). The existence of the MIL-100(Fe)@DPANI heterojunction improved the absorption and utilization of light and promoted the separation of electrons and holes, thereby enhancing the photocatalytic ability and efficiency. Therefore, DPANI not only greatly promoted the growth of MIL-100(Fe), but also significantly enhanced the photocatalytic activity of the composite. After $3 \mathrm{~h}$ adsorption-photocatalysis, the removal ratio of CIP approached $82.78 \%$, and the removal capacity of CIP was as high as $105.96 \mathrm{mg} \mathrm{g}^{-1}$. 


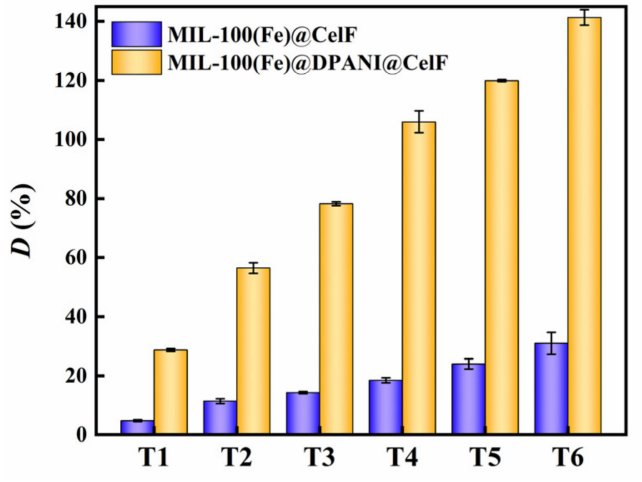

(a)

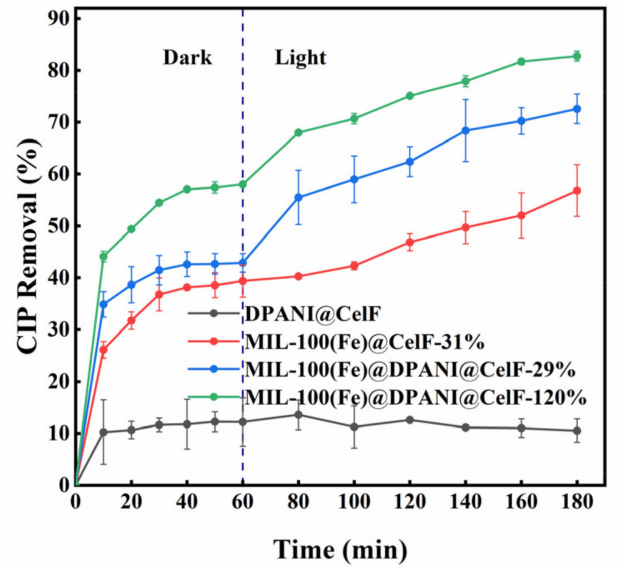

(b)

Figure 5. (a) Comparison of MIL-100(Fe) deposition on CelF and DPANI@CelF; (b) comparison of CIP removal by CelF composites via adsorption-photocatalysis (28\%, 31\% and 120\% refer to the deposition ratios of MIL-100(Fe), 0-60 min for adsorption and 60-180 min for photocatalysis).

\section{Conclusions}

In this work, a universal and efficient platform for in-situ growth and immobilization of MOFs on CelF was proposed. It was found that PANI (especially DPANI) could be used as a mediating layer to promote the in-situ growth and immobilization of some MOFs (particularly MIL-100(Fe)) on CelF. The DPANI layer not only significantly promoted the in-situ growth of MIL-100(Fe) on CelF, but also markedly improved the nanocrystallization of MIL-100(Fe). In addition, MIL-100(Fe)/DPANI heterojunction enhanced the photocatalytic ability of the MIL-100(Fe)@DPANI@CelF composite. A small amount of MIL-100(Fe)@DPANI@CelF composite was used to effectively remove CIP in water; the removal ratio of CIP approached $82.78 \%$ and the removal capacity of CIP was as high as $105.96 \mathrm{mg} \mathrm{g}^{-1}$ after $3 \mathrm{~h}$ of adsorption-photocatalysis. This research realized the efficient combination and utilization of CelF, MOFs and PANI through a green and simple method, and provided new insights for the research and development of MOFs@CelF composites.

Author Contributions: X.H., L.S. and X.Q. designed the experiments; X.H. and Y.H. conducted the experiments; X.H., L.S. and X.A. analyzed the data; X.H. and X.Q. wrote the paper. All authors discussed the results and contributed to the improvement of the final text of the paper. All authors have read and agreed to the published version of the manuscript.

Funding: This work was supported by the National Natural Science Foundation of China (grant no. 31770620).

Institutional Review Board Statement: Not applicable.

Informed Consent Statement: Not applicable.

Data Availability Statement: The authors confirm that the data supporting the findings of this study are available within the article.

Conflicts of Interest: The authors declare no conflict of interest.

\section{References}

1. Hou, C.; Chen, W.; Fu, L.; Zhang, S.; Liang, C.; Wang, Y. Facile synthesis of a Co/Fe bi-MOFs/CNF membrane nanocomposite and its application in the degradation of tetrabromobisphenol A. Carbohydr. Polym. 2020, 247, 116731. [CrossRef] [PubMed]

2. Yang, L.; Cao, L.; Huang, R.; Hou, Z.; Qian, X.; An, B.; Xu, H.; Lin, W.; Wang, C. Two-dimensional metal-organic layers on carbon nanotubes to overcome conductivity constraint in electrocatalysis. ACS Appl. Mater. Inter. 2018, 10, 36290-36296. [CrossRef] [PubMed]

3. Rubin, H.N.; Neufeld, B.H.; Reynolds, M.M. Surface-anchored metal-organic framework-cotton material for tunable antibacterial copper delivery. ACS Appl. Mater. Inter. 2018, 10, 15189-15199. [CrossRef] [PubMed] 
4. Li, H.; Wang, K.; Sun, Y.; Lollar, C.T.; Li, J.; Zhou, H. Recent advances in gas storage and separation using metal-organic frameworks. Mater. Today 2018, 21, 108-121. [CrossRef]

5. Guo, R.; Cai, X.; Liu, H.; Yang, Z.; Meng, Y.; Chen, F.; Li, Y.; Wang, B. In situ growth of metal-organic frameworks in threedimensional aligned lumen arrays of wood for rapid and highly efficient organic pollutant removal. Environ. Sci. Technol. 2019, 53, 2705-2712. [CrossRef]

6. Javanbakht, S.; Pooresmaeil, M.; Namazi, H. Green one-pot synthesis of carboxymethylcellulose/Zn-based metal-organic framework/graphene oxide bio-nanocomposite as a nanocarrier for drug delivery system. Carbohydr. Polym. 2019, 208, $294-301$. [CrossRef]

7. Zhu, L.; Zong, L.; Wu, X.; Li, M.; Wang, H.; You, J.; Li, C. Shapeable fibrous aerogels of metal-organic-frameworks templated with nanocellulose for rapid and large-capacity adsorption. ACS Nano 2018, 12, 4462-4468. [CrossRef]

8. Mahmoodi, N.M.; Oveisi, M.; Taghizadeh, A.; Taghizadeh, M. Synthesis of pearl necklace-like ZIF-8@chitosan/PVA nanofiber with synergistic effect for recycling aqueous dye removal. Carbohydr. Polym. 2020, 227, 115364. [CrossRef]

9. Guan, X.; Lin, S.; Lan, J.; Shang, J.; Li, W.; Zhan, Y.; Xiao, H.; Song, Q. Fabrication of Ag/ AgCl/ZIF-8/TiO 2 decorated cotton fabric as a highly efficient photocatalyst for degradation of organic dyes under visible light. Cellulose 2019, 26, 7437-7450. [CrossRef]

10. Bian, W.; Chen, J.; Chen, Y.; Xu, W.; Jia, J. A novel waste paper cellulose-based Cu-MOF hybrid material threaded by PSS for lithium extraction with high adsorption capacity and selectivity. Cellulose 2021, 28, 3041-3054. [CrossRef]

11. Bhat, A.H.; Khan, I.; Usmani, M.A.; Umapathi, R.; Al-Kindy, S.M.Z. Cellulose an ageless renewable green nanomaterial for medical applications: An overview of ionic liquids in extraction, separation and dissolution of cellulose. Int. J. Biol. Macromol. 2019, 129, 750-777. [CrossRef]

12. Ma, S.; Zhang, M.; Nie, J.; Yang, B.; Song, S.; Lu, P. Multifunctional cellulose-based air filters with high loadings of metal-organic frameworks prepared by in situ growth method for gas adsorption and antibacterial applications. Cellulose 2018, 25, 5999-6010. [CrossRef]

13. Karmakar, S.; Bhattacharjee, S.; De, S. Experimental and modeling of fluoride removal using aluminum fumarate (AlFu) metal organic framework incorporated cellulose acetate phthalate mixed matrix membrane. J. Environ. Chem. Eng. 2017, 5, 6087-6097. [CrossRef]

14. Schelling, M.; Kim, M.; Otal, E.; Hinestroza, J. Decoration of cotton fibers with a water-stable metal-organic framework (UiO-66) for the decomposition and enhanced adsorption of micropollutants in water. Bioengineering 2018, 5, 14. [CrossRef] [PubMed]

15. Ozer, R.R.; Hinestroza, J.P. One-step growth of isoreticular luminescent metal-organic frameworks on cotton fibers. RSC Adv. 2015, 5, 15198-15204. [CrossRef]

16. Laurila, E.; Thunberg, J.; Argent, S.P.; Champness, N.R.; Zacharias, S.; Westman, G.; Ohrstrom, L. Enhanced synthesis of metal-organic frameworks on the surface of electrospun cellulose nanofibers. Adv. Eng. Mater. 2015, 7, 1282-1286. [CrossRef]

17. Wang, N.; Ouyang, X.; Yang, L.; Omer, A.M. Fabrication of a magnetic cellulose nanocrystal/metal-organic framework composite for removal of $\mathrm{Pb}$ (II) from water. ACS Sustain. Chem. Eng. 2017, 5, 10447-10458. [CrossRef]

18. Bo, S.; Ren, W.; Lei, C.; Xie, Y.; Cai, Y.; Wang, S.; Gao, J.; Ni, Q.; Yao, J. Flexible and porous cellulose aerogels / zeolitic imidazolate framework (ZIF-8) hybrids for adsorption removal of Cr(IV) from water. J. Solid State Chem. 2018, 262, 135-141. [CrossRef]

19. Zhu, H.; Yang, X.; Cranston, E.D.; Zhu, S. Flexible and porous nanocellulose aerogels with high loadings of metal-organicframework particles for separations applications. Adv. Mater. 2016, 28, 7652-7657. [CrossRef]

20. Au-Duong, A.N.; Lee, C.K. Flexible metal-organic framework-bacterial cellulose nanocomposite for iodine capture. Cryst. Growth Des. 2018, 18, 356-363. [CrossRef]

21. Silva Pinto, M.D.; Sierra-Avila, C.A.; Hinestroza, J.P. In situ synthesis of a Cu-BTC metal-organic framework (MOF 199) onto cellulosic fibrous substrates: Cotton. Cellulose 2012, 19, 1771-1779. [CrossRef]

22. Duan, C.; Meng, J.; Wang, X.; Meng, X.; Sun, X.; Xu, Y.; Zhao, W.; Ni, Y. Synthesis of novel cellulose-based antibacterial composites of Ag nanoparticles@metal-organic frameworks@carboxymethylated fibers. Carbohydr. Polym. 2018, 193, 82-88. [CrossRef]

23. Zhao, J.; Losego, M.D.; Lemaire, P.C.; Williams, P.S.; Gong, B.; Atanasov, S.E.; Blevins, T.M.; Oldham, C.J.; Walls, H.J.; Shepherd, S.D.; et al. Highly adsorptive, MOF-functionalized nonwoven fiber mats for hazardous gas capture enabled by atomic layer deposition. Adv. Mater. Interfaces 2014, 1, 1400040. [CrossRef]

24. Bao, T.; Su, Y.; Zhang, N.; Gao, Y.; Wang, S. Hydrophilic carboxyl cotton for in situ growth of UiO-66 and its application as adsorbents. Ind. Eng. Chem. Res. 2019, 58, 20331-20339. [CrossRef]

25. Zha, J.; Yin, X.; Baltzegar, J.R.; Zhang, X. Coordinatively unsaturated metal site-promoted selective adsorption of organic molecules on supported metal-organic framework nanosheets. Langmuir 2019, 35, 12908-12913. [CrossRef] [PubMed]

26. Abdelhameed, R.M.; Kamel, O.M.H.M.; Amr, A.; Rocha, J.; Silva, A.M.S. Antimosquito activity of a titanium-organic framework supported on fabrics. ACS Appl. Mater. Inter. 2017, 9, 22112-22120. [CrossRef] [PubMed]

27. Shen, C.; Mao, Z.; Xu, H.; Zhang, L.; Zhong, Y.; Wang, B.; Feng, X.; Tao, C.; Sui, X. Catalytic MOF-loaded cellulose sponge for rapid degradation of chemical warfare agents simulant. Carbohydr. Polym. 2019, 213, 184-191. [CrossRef]

28. Liu, Q.; Yu, H.; Zeng, F.; Li, X.; Sun, J.; Hu, X.; Pan, Q.; Li, C.; Lin, H.; Su, Z. Polyaniline as interface layers promoting the in-situ growth of zeolite imidazole skeleton on regenerated cellulose aerogel for efficient removal of tetracycline. J. Colloid Interf. Sci. 2020, 579, 119-127. [CrossRef]

29. Yu, M.; Qian, X.; Zhou, W. Photocatalytic activity of CdS@polyaniline/cellulose fibers composite. Chem. Ind. For. Prod. 2018, 38, 115-121. 
30. Xing, S.; Li, W.; Liu, B.; Wu, Y.; Gao, Y. Removal of ciprofloxacin by persulfate activation with CuO: A pH-dependent mechanism. Chem. Eng. J. 2020, 382, 122837. [CrossRef]

31. Li, H.; Wu, W.; Hao, X.; Wang, S.; You, M.; Han, X.; Zhao, Q.; Xing, B. Removal of ciprofloxacin from aqueous solutions by ionic surfactant-modified carbon nanotubes. Environ. Pollut. 2018, 243, 206-217. [CrossRef] [PubMed]

32. Mao, J.; Hong, B.; Wei, J.; Xu, J.; Han, Y.; Jin, H.; Jin, D.; Peng, X.; Li, J.; Yang, Y.; et al. Enhanced ciprofloxacin photodegradation of visible-light-driven $\mathrm{Z}$-scheme $\mathrm{g}-\mathrm{C}_{3} \mathrm{~N}_{4} / \mathrm{Bi}_{2} \mathrm{WO}_{6}$ nanocomposites and interface effect. ChemistrySelect 2019, 4, 13716-13723. [CrossRef]

33. Lu, W.; Duan, C.; Zhang, Y.; Gao, K.; Dai, L.; Shen, M.; Wang, W.; Wang, J.; Ni, Y. Cellulose-based electrospun nanofiber membrane with core-sheath structure and robust photocatalytic activity for simultaneous and efficient oil emulsions separation, dye degradation and Cr(VI) reduction. Carbohydr. Polym. 2021, 258, 117676. [CrossRef] [PubMed]

34. Wu, L.; Wang, C.; Chu, H.; Yi, X.; Wang, P.; Zhao, C.; Fu, H. Bisphenol A cleanup over MIL-100(Fe)/CoS composites: Pivotal role of Fe-S bond in regenerating $\mathrm{Fe}^{2+}$ ions for boosted degradation performance. Chemosphere 2021, 280, 130659. [CrossRef] [PubMed]

35. Wang, C.; Qian, X.; An, X. In situ green preparation and antibacterial activity of copper-based metal-organic frameworks/cellulose fibers (HKUST-1/CF) composite. Cellulose 2015, 22, 3789-3797. [CrossRef]

36. Lu, W.; Duan, C.; Liu, C.; Zhang, Y.; Meng, X.; Dai, L.; Wang, W.; Yu, H.; Ni, Y. A self-cleaning and photocatalytic cellulosefiber-supported “Ag@AgCl@MOF-cloth" membrane for complex wastewater remediation. Carbohydr. Polym. 2020, $247,116691$. [CrossRef]

37. Tanaka, S.; Kida, K.; Okita, M.; Ito, Y.; Miyake, Y. Size-controlled synthesis of zeolitic imidazolate framework-8 (ZIF-8) crystals in an aqueous system at room temperature. Chem. Lett. 2012, 41, 1337-1339. [CrossRef]

38. Kuruppathparambil, R.R.; Jose, T.; Babu, R.; Hwang, G.Y.; Kathalikkattil, A.C.; Kim, D.W.; Park, D.W. A room temperature synthesizable and environmental friendly heterogeneous ZIF-67 catalyst for the solvent less and co-catalyst free synthesis of cyclic carbonates. Appl. Catal. B-Environ. 2016, 182, 562-569. [CrossRef]

39. Oveisi, M.; Mahmoodi, N.M.; Asli, M.A. Facile and green synthesis of metal-organic framework/inorganic nanofiber using electrospinning for recyclable visible-light photocatalysis. J. Clean. Prod. 2019, 222, 669-684. [CrossRef] 